\title{
Recurrent Abdominal Arterial Aneurysm Rupture
}

\author{
Masahiro Kashiura and Yuichi Hamabe
}

Key words: Ehlers-Danlos syndrome, ruptured aneurysm, therapeutic embolization

(Intern Med 55: 3543-3544, 2016)

(DOI: 10.2169/internalmedicine.55.7183)

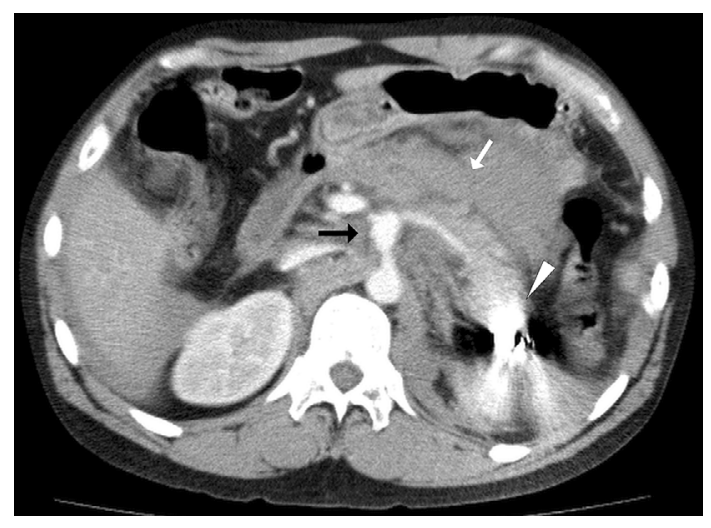

Picture 1.

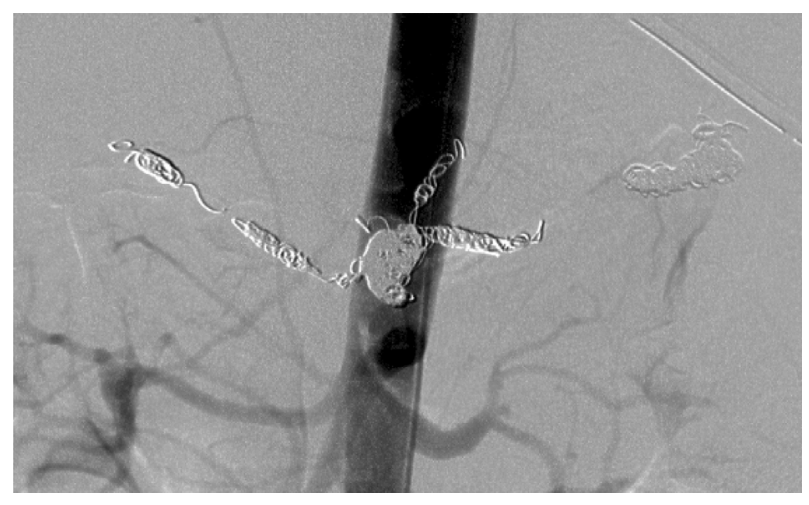

Picture 3.

A 37-year-old man presented to the emergency department with abdominal pain and shock. He underwent endovascular embolization for splenic arterial aneurysm rupture caused by Ehlers-Danlos syndrome, which had been confirmed by genetic testing three years prior. Computed tomography showed an intra-abdominal hemorrhage, celiac arterial aneurysm, and embolic coils in the splenic artery (Picture 1, white and black arrows and arrowhead, respectively). Emergency angiography also showed a celiac arterial aneu-

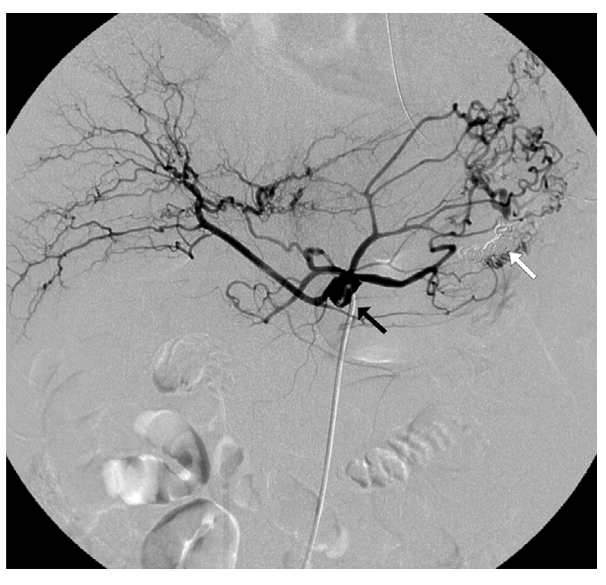

Picture 2.

rysm without contrast extravasation and an embolic coil in the splenic artery (Picture 2, black and white arrows, respectively). The successful occlusion of the celiac artery aneurysm and its branches was achieved using Interlock Fibered IDC coils (Boston Scientific, Natick, MA, USA) (Picture 3). The patient was discharged on postoperative day 17 without abdominal organ ischemia. Arterial aneurysm rupture is a life-threatening complication of vascular Ehlers-Danlos syndrome (1). Arterial aneurysm rupture can occur repeatedly; therefore, long-term follow-up is necessary with $\beta 1$ antagonist administration and regular non-invasive imaging examinations $(1,2)$.

The authors state that they have no Conflict of Interest (COI).

\section{References}

1. Bergqvist D, Björck M, Wanhainen A. Treatment of vascular Ehlers-Danlos syndrome: a systematic review. Ann Surg 258: 257261, 2013.

2. Ong KT, Perdu J, De Backer J, et al. Effect of celiprolol on prevention of cardiovascular events in vascular Ehlers-Danlos syndrome: a prospective randomised, open, blinded-endpoints trial.

Tertiary Emergency Medical Center, Tokyo Metropolitan Bokutoh Hospital, Japan Received for publication January 25, 2016; Accepted for publication April 6, 2016 Correspondence to Dr. Masahiro Kashiura, kashiura@me.com 
Intern Med 55: 3543-3544, 2016 DOI: 10.2169/internalmedicine.55.7183

Lancet 376: 1476-1484, 2010.

The Internal Medicine is an Open Access article distributed under the Creative
Commons Attribution-NonCommercial-NoDerivatives 4.0 International License. To view the details of this license, please visit (https://creativecommons.org/licenses/ by-nc-nd/4.0/).

(C) 2016 The Japanese Society of Internal Medicine http://www.naika.or.jp/imonline/index.html 